Scott R. Smith, Chunqing Zhou, Janet Y. Baron, Yeonuk Choi, Jacek Lipkowski, "Elucidating the Interfacial Interactions of Copper and Ammonia with the Sulfur Passive Layer during Thiosulfate Mediated Gold Leaching”, Electrochim Acta, 2016,210,925-939

\title{
Elucidating the Interfacial Interactions of Copper and Ammonia with the Sulfur Passive Layer during Thiosulfate Mediated Gold Leaching
}

\author{
Scott R. Smith ${ }^{1}$, Chunqing Zhou ${ }^{1}$, Janet Y. Baron ${ }^{2}$, Yeonuk Choi ${ }^{3}$, Jacek Lipkowski ${ }^{1 *}$ \\ ${ }^{I}$ Department of Chemistry, University of Guelph, Guelph, ON N1G 2W1, Canada \\ ${ }^{2}$ Barrick Gold Corporation, Goldstrike, NV 89822, United States \\ ${ }^{3}$ Barrick Gold Corporation, Toronto, ON M5J 2S1, Canada \\ *Corresponding author: jlipkows@uoguelph.ca
}

\begin{abstract}
Characterization of copper and ammonia interactions with the passive layer that impedes gold dissolution with thiosulfate based electrolytes at extended time frames was performed with electrochemistry and shell-isolated nanoparticle-enhanced Raman spectroscopy (SHINERS). Generalized two-dimensional correlation spectroscopy (2DCOS) was also employed to assist interpretation of the collected SHINERS spectra. Growth of the complex passive layer mixture on a polycrystalline gold electrode immersed in a $0.10 \mathrm{M} \mathrm{Na}_{2} \mathrm{~S}_{2} \mathrm{O}_{3}$ electrolyte was found to initially proceed through formation of sulfides adsorbed to the gold electrode surface (SERS band at ca. 326 and $\left.309 \mathrm{~cm}^{-1}\right)$ followed by rapid transformation to cyclo-S 8 (474, 218, and 152 $\mathrm{cm}^{-1}$ ) and polysulfides/polythionates $\left(459 \mathrm{~cm}^{-1}\right)$. After stable formation of the passive film, the addition of $\mathrm{Cu}^{2+}$ resulted in the partial removal of the passive layer. The removal of the components of the passive layer proceeded according to the following sequence; polysulfides were fastest, cyclo- $S_{8}$ next, followed by $S_{(\text {ads })}^{2-}$. The end product was observed to be a combination of copper and gold sulfides. In an independent study, the addition of ammonia displayed a similar ability to remove the passive layer constituents, albeit at much slower rates. From these observations it can be concluded that copper and ammonia play a vital function in preventing passive layer formation, allowing increased mass transport of thiosulfate and the oxidant across the electrode-electrolyte interface, thereby allowing a higher gold extraction efficiency.
\end{abstract}

Keywords: shell-isolated nanoparticle-enhanced Raman spectroscopy, electrochemistry, twodimensional correlation spectroscopy, thiosulfate gold leaching, sulfur passive layer. 


\section{Introduction}

The suitability of thiosulfate as an alternative complexing ligand in gold lixiviant solutions designed for hydrometallurgical extraction of gold is limited by the generation of passivating species that inhibit the mass transport of reactants and products across the interfacial region [1-9]. The surface enhanced Raman spectroscopy (SERS) is a surface sensitive technique that has the benefit of identifying the interfacial species in situ leading to a deeper understanding of the dissolution mechanism and to study how passive layer is formed at the gold-electrolyte interface. Previously, gold nanostructures employed to achieve sufficient Raman enhancement at the gold surface exposed to the gold lixiviant were quickly dissolved into the electrolyte [1-6]. Recently, we have shown that shell-isolated nanoparticles (SHINs), which are gold nanoparticles encapsulated in a uniform silica shell (typically $2-5 \mathrm{~nm}$ in thickness), are stable in typical gold leaching conditions and are capable of sustaining sufficient surface enhancement for 24 hours due to the protective silica coating that prevents dissolution of the gold nanoparticle core [10].

Using shell-isolated nanoparticle enhanced Raman spectroscopy (SHINERS) the generation of the soluble gold-thiosulfate complex as the predominant product upon initial exposure of a gold electrode to a thiosulfate lixiviant solution was observed [10]. However, the spectra collected of the SHINs modified polycrystalline gold electrode (Au/SHINs) after $\sim 1000$ mins exposure to a $0.10 \mathrm{M} \mathrm{Na} \mathrm{S}_{2} \mathrm{O}_{3}$ lixiviant, see Figure 1, displays several broad and overlapping bands characteristic of many adsorbed species like thiosulfate, the gold-thiosulfate complex, sulfur/sulfides (i.e. $\left.\mathrm{Au}_{2} \mathrm{~S}\right)$, cyclo- $\mathrm{S}_{8}$, and polysulfide/polythionate chains $\left(\mathrm{S}_{n} / \mathrm{S}_{n}^{2-}\right)$ of varying lengths. Assignment of the bands observed in the spectra are based on a combination of; (i) previous reports of SERS spectra recorded of species adsorption from their respective pure electrolytes $[1,3,6]$, (ii) theoretical calculations, and (iii) spectral analysis methods like Fourier self-deconvolution (FSD) or generalized two-dimensional correlation spectroscopy (2DCOS) [10]. The SERS spectra show that the thiosulfate lixiviant slowly decomposes on gold surfaces forming monoatomic adsorbed sulfur/sulfide, followed by formation of cyclo- $\mathrm{S}_{8}$ and finally polysulfides/polythionates $[6,10]$. The formation of these elemental sulfur species at the goldelectrolyte interface inhibit the mass transport of reactants/products to and from the gold surface, and are therefore the primary cause for low gold extraction in industrial leaching practices.

Several studies investigated the potential of several additives to increase the gold extraction efficiency during thiosulfate based leaching. For example, redox couples (e.g. $\mathrm{Cu}^{2+/+}$ ) [1,5], ammonia (e.g. $\mathrm{NH}_{3} / \mathrm{NH}_{4}{ }^{+}$) [11-13], alkylthiols (e.g. $\mathrm{RSH}$ ) [4,14], thiourea [15], sulfite [16], and ethylenediaminetetraacetic acid (EDTA) [17,18] have been suggested to improve the gold leaching kinetics in thiosulfate solutions [4,8,15,16,19-21]. In particular, the copper redox couple has been suggested as a better oxidant relative to dissolved oxygen due to increased solubility and mass transport to the gold surface in typical leaching conditions [7]. The overall leaching process, with copper as the supporting oxidant, is the combination of the electrochemical reduction of $\mathrm{Cu}^{2+}$ to $\mathrm{Cu}^{+}$and the oxidation of $\mathrm{Au}(0)$ to $\mathrm{Au}(\mathrm{I})$ in the presence of excess thiosulfate $[1,7,8,22]$ :

$$
\mathrm{Au}^{0}+3 \mathrm{~S}_{2} \mathrm{O}_{3}^{2-}+\left[\mathrm{Cu}\left(\mathrm{S}_{2} \mathrm{O}_{3}\right)_{2}\right]^{2-} \rightleftarrows\left[\mathrm{Cu}\left(\mathrm{S}_{2} \mathrm{O}_{3}\right)_{3}\right]^{5-}+\left[\mathrm{Au}\left(\mathrm{S}_{2} \mathrm{O}_{3}\right)_{2}\right]^{3-}
$$

Amines, specifically ammonia $(\mathrm{pKa}=9.24)$, have also been suggested to improve the gold extraction efficiency in thiosulfate-oxygen leaching systems $(\mathrm{pH}=8-10)$ through assisting 
in surface processes like gold dissolution and transport of gold atoms into the bulk electrolyte according to [23]:

$$
4 \mathrm{Au}^{0}+\mathrm{O}_{2}+8 \mathrm{NH}_{3}+2 \mathrm{H}_{2} \mathrm{O} \rightleftarrows 4\left[\mathrm{Au}\left(\mathrm{NH}_{3}\right)_{2}\right]^{+}+4 \mathrm{OH}^{-}
$$

The stability constants have been previously reported to be similar for the gold-ammonia and gold-thiosulfate complexes in the bulk solution [7,23-26], but suggests free thiosulfate in solution will compete with ammonia as a ligand to form the thermodynamically favoured goldthiosulfate complexes through [7]:

$$
\left[\mathrm{Au}\left(\mathrm{NH}_{3}\right)_{2}\right]^{+}+2 \mathrm{~S}_{2} \mathrm{O}_{3}^{2-} \rightleftarrows\left[\mathrm{Au}\left(\mathrm{S}_{2} \mathrm{O}_{3}\right)_{2}\right]^{3-}+2 \mathrm{NH}_{3}
$$

However, gold may also be leached directly into the aqueous ammonia-thiosulfate electrolyte as mixed ligand complexes according to [23]:

$$
4 \mathrm{Au}^{0}+\mathrm{O}_{2}+4 \mathrm{NH}_{3}+4 \mathrm{~S}_{2} \mathrm{O}_{3}^{2-}+2 \mathrm{H}_{2} \mathrm{O} \rightleftarrows 4\left[\mathrm{Au}\left(\mathrm{NH}_{3}\right)\left(\mathrm{S}_{2} \mathrm{O}_{3}\right)\right]^{-}+4 \mathrm{OH}^{-}
$$

Nie et al. have recently suggested that the chemical interaction of ammonia with the passive layer constituents on the gold surface in thiosulfate electrolytes can significantly alter the gold leaching kinetics [13].

In addition to aiding in gold dissolution, ammonia is commonly reported as a second additive to stabilize copper(II) and prevent high rates of thiosulfate consumption $[5,7,8,20,23,27,28]$. In the presence of copper and ammonia the gold oxidation and subsequent dissolution in the thiosulfate leaching system is believed to occur via reduction of the copper(II) tetraammonia complex coupled with the exchange of two ammonia ligands to form a gold(I)ammonia complex as described by:

$$
\mathrm{Au}^{0}+\left[\mathrm{Cu}\left(\mathrm{NH}_{3}\right)_{4}\right]^{2+}+3 \mathrm{~S}_{2} \mathrm{O}_{3}^{2-} \rightleftarrows\left[\mathrm{Au}\left(\mathrm{NH}_{3}\right)_{2}\right]^{+}+\left[\mathrm{Cu}\left(\mathrm{S}_{2} \mathrm{O}_{3}\right)_{3}\right]^{5-}+2 \mathrm{NH}_{3}
$$

Following Equation 3, free thiosulfate ions are then able to displace the ammonia ligands to produce the gold(I) thiosulfate complex. As been suggested by Molleman and Dreisinger [21], and more recently by Lampinen et al. [11], it is extremely important to control the thiosulfate to ammonia ratio for regeneration of the copper tetraammonia complex, Equation 6, and ensuring a high extraction efficiency of gold from the host ore.

$$
4\left[\mathrm{Cu}\left(\mathrm{S}_{2} \mathrm{O}_{3}\right)_{3}\right]^{5-}+16 \mathrm{NH}_{3}+\mathrm{O}_{2}+2 \mathrm{H}_{2} \mathrm{O} \rightleftarrows 4\left[\mathrm{Cu}\left(\mathrm{NH}_{3}\right)_{4}\right]^{2+}+12 \mathrm{~S}_{2} \mathrm{O}_{3}^{2-}+4 \mathrm{OH}^{-}(\mathrm{EQ} 6)
$$

In addition to assisting in the gold dissolution reaction, many additives may play a more complex role in gold extraction at extended time scales, by inhibiting the formation of the passive layer or by inhibiting or degrading the elemental sulfur species known to passivate the gold electrode surface. Most literature to date has focused on the cooperativity of copper and ammonia added together to the thiosulfate leaching system. Unfortunately, the reported literature has lacked direct evidence of the interaction by which each of these particular additives influence the overall gold extraction efficiency. A better understanding of the nature of copper and ammonia interactions with the sulfur passive layer formed in the interfacial region is paramount for maintaining high gold extraction efficiencies in industrial conditions. Previously, we have reported a procedure employing shell-isolated nanoparticle-enhanced Raman spectroscopy (SHINERS) to quantify the relative intensity changes in observed SHINERS bands related to the 
formation of passive layer species under typical leaching conditions [10]. The objective of this study is to independently employ electrochemistry and SHINERS to study the effect of copper and ammonia after passive layer formation in a thiosulfate electrolyte under typical gold leaching conditions. The results presented offer added mechanistic insight into the individual roles that copper and ammonia play in assisting extraction of gold from its host ore.

\section{Materials and Methods}

\subsection{Materials and Substrate Preparations}

Gold nanoparticles (AuNPs, ca. 120nm dia.) were synthesized following the two step seed-mediated growth procedure and encapsulation with a thin silica layer $\left(\mathrm{SiO}_{2}\right.$, ca. $2-5 \mathrm{~nm}$ thickness) as previously outlined by Li et al. [29-32]. The SERS active substrate was prepared by drop coating the SHINs under vacuum onto a freshly polished polycrystalline gold electrode (99.99\% purity). Following the deposition of the SHINs, the gold electrode (Au/SHINs) was placed in a three-electrode glass electrochemical cell, and gently cleaned in an argon purged 0.1 M sodium fluoride electrolyte (NaF, Sigma Aldrich, >99\%), prepared using Milli-Q water (18.2 $\mathrm{M} \Omega \mathrm{cm})$, by repetitive cycling within the double layer region $(-0.70$ to $+0.40 \mathrm{~V}$ vs. SCE) until a stable cyclic voltammogram characteristic of a clean gold surface was achieved. A coiled gold wire (Alfa Aesar, >99.9\%) and a saturated calomel electrode (SCE, Fisher Scientific), connected to the electrolyte solution through a salt bridge, were used as the counter and reference electrodes, respectively.

Thiosulfate electrolyte solutions were prepared fresh prior to every investigation using sodium thiosulfate pentahydrate $\left(\mathrm{Na}_{2} \mathrm{~S}_{2} \mathrm{O}_{3} \cdot 5 \mathrm{H}_{2} \mathrm{O}\right.$, Sigma Aldrich, $\left.\geq 99.5 \%\right)$ dissolved to a $0.10 \mathrm{M}$ concentration in $100 \mathrm{~mL}$ of Milli-Q water $(18.2 \mathrm{M} \Omega \mathrm{cm})$ and adjusted to a final $\mathrm{pH}$ value of 10.0 using sodium hydroxide ( $\mathrm{NaOH}$, Sigma Aldrich, 99.99\%). The $\mathrm{pH}$ was routinely monitored to maintain its value constant throughout each experiment. Copper sulfate pentahydrate $\left(\mathrm{CuSO}_{4} \cdot 5 \mathrm{H}_{2} \mathrm{O}\right.$, Sigma Aldrich, $\left.+98 \%\right)$, or ammonium hydroxide $\left(\mathrm{NH}_{4} \mathrm{OH}\right.$, Fisher Scientific, A.C.S. reagent), were studied as lixiviant additives by first dissolving them in a small aliquot of Milli-Q water, followed by slow addition directly into the thiosulfate lixiviant at $t=0$ min or after the gold electrode had been exposed to the $0.10 \mathrm{M} \mathrm{Na}_{2} \mathrm{~S}_{2} \mathrm{O}_{3}$ electrolyte for 1000 mins and continuing the investigation for several additional hours.

\subsection{Electrochemical Rate of Gold Dissolution}

Kinetics of gold leaching in the presence of thiosulfate was monitored using a modified electrochemical method described previously by Baron et al. which was based on a ButlerVolmer equation [7,33-35]. The gold leaching rate was observed to be extremely dependent on the preparation method of the electrode prior to each measurement. Therefore, a polycrystalline gold electrode was polished with successive grades of diamond suspension $(6,3$, and $1 \mu \mathrm{m}$, LECO) prior to each measurement, introduced into a three electrode electrochemical cell, and then repetitively cycled between $-0.90 \mathrm{~V}$ and $+1.25 \mathrm{~V}$ vs. SCE in a $0.10 \mathrm{M} \mathrm{NaF}$ electrolyte using a HEKA PG590 potentiostat until a clean and stable cyclic voltammogram was obtained. The electrochemically clean, and freshly polished, gold electrode was removed from the electrochemical cell, rinsed with copious quantities of Milli-Q water, and then re-immersed into a new electrochemical cell with a freshly prepared thiosulfate lixiviant at the open circuit potential $\left(E_{\mathrm{OCP}}\right)$. Linear sweep voltammograms $(\mathrm{LSV})$ were recorded $\pm 20 \mathrm{mV}$ of the $E_{\mathrm{OCP}}$, at a sweep rate of $1 \mathrm{mV} \mathrm{s}^{-1}$, every five minutes for the first $60 \mathrm{mins}$, every 10 minutes for the 
following 120 mins, and every 30 mins afterwards. After each LSV the potential was allowed to return to $E_{\mathrm{OCP}}$ to minimize perturbation of the passive layer and the leaching rate. The mixed leaching current, $i_{\mathrm{M}}$, was calculated from the slope of the collected LSV using independently determined transfer coefficients $\alpha_{\mathrm{O}_{2}}$ and $\alpha_{\mathrm{Au}}$ of 0.53 and 0.23 , respectively [9,35]. The calculated values of $i_{\mathrm{M}}$ were converted to the rate of gold dissolution $\left(R_{\mathrm{Au}}\right.$ in units of $\mathrm{nmol} \mathrm{m}^{-2}$ 
$\mathrm{s}^{-1}$ ) using the Faraday law and plotted as a function of exposure time of the electrode surface to the thiosulfate lixiviant.

\subsection{Spectral Instrumentation and Analysis}

A Renishaw Raman imaging microscope equipped with a $785 \mathrm{~nm}$ NIR diode laser (300 $\mathrm{mW}$ power) and a CCD array detector was used for all Raman investigations. A spectral resolution of approximately $1 \mathrm{~cm}^{-1}$ was achieved using a holographic grating (1200 grooves $\mathrm{mm}^{-1}$ ) and a slit width of $50 \mu \mathrm{m}$. The spectrometer was calibrated to the vibrational Raman band of silicon ca. $521 \mathrm{~cm}^{-1}$ prior to each experiment. Complete encapsulation of the SHINs was confirmed by recording a SERS spectra of the SHINs deposited on a clean silicon wafer and immersed in a $0.01 \mathrm{M}$ pyridine solution $\left(\mathrm{C}_{5} \mathrm{H}_{5} \mathrm{~N}\right.$, Fisher Sci., certified ACS reagent grade) with a $100 \%$ laser power, $1 \mathrm{~s}$ exposure, and 3 accumulations. All gold leaching investigations were performed using a custom built Teflon spectroelectrochemical cell designed to fit the Au/SHINs electrode in an inverted configuration $\left(180^{\circ}\right.$ geometry). All leaching investigations were conducted in open atmosphere to allow the exchange of dissolved oxygen in the thiosulfate electrolyte. A LEICA immersion lens (63x) was immersed directly into the electrolyte solution and focused onto the electrode/substrate surface. All SHINERS studies were collected in a single acquisition between 3200 to $100 \mathrm{~cm}^{-1}$ at regular time intervals with a laser power of approximately $15 \mathrm{~mW}$ at the sample, exposure time of $10 \mathrm{~s}$, and 3 accumulations.

The SERS intensities plotted versus time were normalized following a previously published procedure [10]. In short, a background SHINERS spectrum was recorded of the clean $\mathrm{Au} / \mathrm{SHINs}$ electrode immersed in Milli-Q water. The Milli-Q water was carefully aspirated and replaced with the desired thiosulfate leaching solution. Upon lixiviant exposure, the spectral intensity of all sequentially acquired SHINERS spectra were normalized at $v_{t=x}\left(2883 \mathrm{~cm}^{-1}\right)$ to the $v_{t=0}\left(2883 \mathrm{~cm}^{-1}\right)$ of the background spectrum to remove changes in the surface enhancement effect. Background removal of the normalized thiosulfate spectrum was accomplished by subtraction of the background spectrum, followed by baseline correction. Finally, the corrected band intensities of the passive layer species were normalized to the observed intensity at $t=1000$ min, whereas, the bands related to the gold-thiosulfate complex were normalized at $t=0 \mathrm{~min}$.

Generalized two-dimensional correlation spectroscopy (2DCOS) spectra [36-39] were generated from the dynamic SHINERS spectra using 2Dshige (C) software form Shigeaki Morita, Kwansei-Gakuin University (2004-2005). Briefly, 2DCOS analysis provides a 2D spectrum generated from a collection of sequentially acquired spectra in which the band intensities changed as a function of immersion time in the thiosulfate solution. The analysis gives two types of correlations, synchronous 2DCOS spectra resulting from simultaneous changes and asynchronous 2DCOS spectra, which arise from sequential or unsynchronized changes in the measured spectral series. The autocorrelation peaks are observed as positive symmetric peaks along the diagonal, $v_{1}=v_{2}$, in the synchronous 2DCOS spectra. These autocorrelation peaks represent variation in the spectral intensity that occurs as a function of time at that particular frequency. A strong autocorrelation peak suggests that the change in the spectral band is strong as a function of time, while weak autocorrelation peaks or the absence of an autocorrelation peak indicate that the spectra are weakly dependent on time. Cross-correlation peaks are found in the off-diagonal positions in synchronous 2DCOS spectra, $v_{1} \neq v_{2}$. Positive cross-peaks indicate that bands at $v_{1}$ and $v_{2}$ increase/decrease simultaneously, while negative cross-peaks imply that one 
band is increasing while the other band is decreasing as a function of time. A correlation square, which illustrates the existence of coherent variations in the spectral intensities at $v_{1}$ and $v_{2}$, can be obtained by connecting a pair of cross-correlation peaks positioned on opposite sides of the diagonal through the corresponding autocorrelation peaks. Thus, the synchronous $2 \mathrm{D}$ spectrum can help remove the ambiguity in the band deconvolution procedure by providing the number of peaks and their corresponding positions. In contrast to the synchronous spectra, asynchronous spectra are antisymmetric with respect to the diagonal, and therefore, no autocorrelation peaks are observed. If the intensity variation in two Raman bands occurs completely synchronized, then no cross correlation peak will be observed in the asynchronous spectra. Again, crosscorrelation peaks in asynchronous spectra can be either positive or negative as in synchronous spectra. If the sign of an asynchronous cross-correlation peak matches the sign of the synchronous cross peak, then the change of band intensity at $v_{1}$ takes place first and is followed by the change at $v_{2}$. If the signs of the synchronous and asynchronous cross-correlation peaks are opposite, then the change in the band intensity at $v_{2}$ takes place before the change at $v_{1}$. Therefore, the asynchronous spectrum can provide information about the sequence of spectral changes.

\section{Results and Discussion}

\subsection{Gold leaching in thiosulfate solution with ammonia}

Figures $2 \mathrm{~A}$ and $2 \mathrm{~B}$ display the average electrochemical mixed potentials, $E_{\mathrm{M}}$ (top panel, Figure $2 \mathrm{~A}$ ), and gold leaching rates, $R_{\mathrm{Au}}$ in units of nmol m $\mathrm{m}^{-2} \mathrm{~s}^{-1}$ (middle panel, Figure $2 \mathrm{~B}$ ), calculated from the current voltage curves recorded after immersing a polycrystalline gold electrode into two different electrolyte solutions during $2500 \mathrm{~min}$ of gold leaching. The black curves, marked with ( $\mathbf{\square})$, plot the results for the $0.10 \mathrm{M} \mathrm{Na}_{2} \mathrm{~S}_{2} \mathrm{O}_{3}(\mathrm{pH}=10.0)$ solution. The initial $E_{\mathrm{M}}$ and $R_{\mathrm{Au}}$ values are $-0.112 \pm 0.014 \mathrm{~V}$ vs. SCE and $11.5 \pm 1.5 \mathrm{nmol} \mathrm{m}^{-2} \mathrm{~s}^{-1}$, respectively. Error bars were excluded from Figure 2 for clarity. The $E_{\mathrm{M}}$ and $R_{\mathrm{Au}}$ decrease quite quickly during the first $50 \mathrm{~min}$ to $E_{\mathrm{M}} \approx-0.144 \pm 0.006 \mathrm{~V}$ vs. SCE and $R_{\mathrm{Au}} \approx 5.2 \pm 1.8 \mathrm{nmol} \mathrm{m}^{-2} \mathrm{~s}^{-1}$. After this initial change, $E_{\mathrm{M}}$ increases and $R_{\mathrm{Au}}$ decreases slowly in a quasi linear fashion. A large variance in the gold dissolution rate has been reported in the literature due to a number of reasons which include; (i) types of reagents used, (ii) differences in reagent concentrations, $\mathrm{pH}$, and temperature, (iii) presence of different additives, (iv) different substrate preparation/cleaning methods and/or (v) the analytical technique employed to measure the leaching rate. $R_{\mathrm{Au}}$ values ranging from $10^{-5}$ to $10^{-8} \mathrm{~mol} \mathrm{~m}^{-2} \mathrm{~s}^{-1}[4,5,35,40,41]$ have been reported for thiosulfate leaching systems. The values reported here are consistent with the lower end of these rates. The observed decrease in the leaching rate corresponds very well with the previously reported decrease in the quantity of the gold-thiosulfate complex in the interfacial region and the concomitant increase in adsorbed monatomic sulfur, cyclic sulfur and polysulfides/polythionates which comprise the passive layer that is believed to inhibit the gold dissolution reaction [10].

The green curves marked with ( $\diamond)$ in Figures $2 \mathrm{~A}$ and $2 \mathrm{~B}$ plot data for the $0.10 \mathrm{M} \mathrm{Na}_{2} \mathrm{~S}_{2} \mathrm{O}_{3}$ $+50 \mathrm{mM} \mathrm{NH}_{4} \mathrm{OH}(\mathrm{pH}=10.0)$ electrolyte. The $E_{\mathrm{M}}$ and $R_{\mathrm{Au}}$ values display similar changes to that observed for the $0.10 \mathrm{M} \mathrm{Na}_{2} \mathrm{~S}_{2} \mathrm{O}_{3}$ solution. Their initial values $-0.118 \mathrm{~V}$ and $10.8 \mathrm{nmol} \mathrm{m}^{-2} \mathrm{~s}^{-1}$, are within the experimental error equal to the corresponding initial values in the solution without ammonia. However, with increasing leaching time the $E_{\mathrm{M}}$ decreases to a value about $50 \mathrm{mV}$ more negative, ca. $-0.168 \mathrm{~V}$, and correspondingly the $R_{\mathrm{Au}}$ value remains higher than in the 0.10 $\mathrm{M} \mathrm{Na}_{2} \mathrm{~S}_{2} \mathrm{O}_{3}$ electrolyte, during the first $1000 \mathrm{~min}$ of the leaching time. At leaching times longer than 1200 min the leaching rates become equal in these two electrolytes. The increase in the $R_{\mathrm{Au}}$ 
in the presence of ammonia relative to the $\mathrm{Na}_{2} \mathrm{~S}_{2} \mathrm{O}_{3}$ electrolyte supports the previous suggestions that ammonia plays an important but convoluted role in aiding gold dissolution [7]. However, while the observed change in the $E_{\mathrm{M}}$ upon ammonia addition appears quite significant, the relatively small change in $R_{\mathrm{Au}}$ is within the standard error. It is believed that after a long exposure of the gold surface to the $\mathrm{Na}_{2} \mathrm{~S}_{2} \mathrm{O}_{3}$ electrolyte multilayers of passive species are likely present at the gold surface and the addition of a small quantity of ammonia may only be able to remove a small portion of this layer which results in shifting the $E_{\mathrm{M}}$ by $50 \mathrm{mV}$ but not able to change $R_{\text {Au }}$ to a significant extent.

To demonstrate that ammonia weakens the passive layer, a third experiment was performed in which $50 \mathrm{mM} \mathrm{NH} 4 \mathrm{OH}$ were added to the $0.10 \mathrm{M} \mathrm{Na}_{2} \mathrm{~S}_{2} \mathrm{O}_{3}(\mathrm{pH}=10.0)$ electrolyte after 1000 min of leaching time had elapsed. These data are marked as $(\mathbf{\Delta})$ in Figures $2 \mathrm{~A}$ and $\mathrm{B}$. During $500 \mathrm{~min}$ after the addition of $50 \mathrm{mM} \mathrm{NH} 4 \mathrm{OH}, E_{\mathrm{M}}$ decreases and $R_{\mathrm{Au}}$ increases to values slightly above the rates observed during continuous leaching in the $0.10 \mathrm{M} \mathrm{Na}_{2} \mathrm{~S}_{2} \mathrm{O}_{3}+50 \mathrm{mM}$ $\mathrm{NH}_{4} \mathrm{OH}(\mathrm{pH}=10.0)$ solution. At longer times (after $1500 \mathrm{~min}$ ), the leaching rates become approximately equal in all three experiments. This experiment suggests that the addition of the $\mathrm{NH}_{4} \mathrm{OH}$ plays a role in degrading the passive layer and allowing the rate of gold leaching to increase, if there is enough $\mathrm{NH}_{4} \mathrm{OH}$ to remove a significant portion of the passive layer that exposes the underlying gold surface for further gold dissolution.

To further demonstrate the interfacial role that ammonia plays as an additive, molecular identification of the species present in the interfacial region is needed. For that purpose SHINERS was employed using a SHINs modified polycrystalline gold electrode (Au/SHINs). The spectra acquisition and analysis followed the procedure described in detail in the earlier publication [10]. The SHINERS spectra were recorded continuously before and after addition of ammonia to the $0.10 \mathrm{M} \mathrm{Na}_{2} \mathrm{~S}_{2} \mathrm{O}_{3}$ solution repeating experiment 3 , where the data is marked as $(\Delta)$ in Figures 2A and 2B. The spectra recorded during the first 1000 min of gold leaching in the $0.10 \mathrm{M} \mathrm{Na}_{2} \mathrm{~S}_{2} \mathrm{O}_{3}$ solution were in a very good agreement with the data presented in ref [10] and hence they are not shown here. After $1000 \mathrm{~min}$ exposure to a $0.10 \mathrm{M} \mathrm{Na}_{2} \mathrm{~S}_{2} \mathrm{O}_{3}$ electrolyte the passive layer formed at the interface is observed to predominantly consist of several sulfur species, most notably, sulfides, cyclo- $\mathrm{S}_{8}$, and polysulfide $\left(\mathrm{S}_{n} / \mathrm{S}_{n}^{2-}\right)$ or polythionate $\left(\mathrm{S}_{n} \mathrm{O}_{y}^{2-}\right)$ chains of variable length, as shown in Figure 1. The composition of the passive layer becomes stable and therefore approximately time independent after $1000 \mathrm{~min}$ exposure of the Au/SHINs electrode to $0.10 \mathrm{M} \mathrm{Na}_{2} \mathrm{~S}_{2} \mathrm{O}_{3}$.

Here, we show only spectra acquired after addition of $50 \mathrm{mM} \mathrm{NH} 4 \mathrm{OH}$ to the $0.10 \mathrm{M}$ $\mathrm{Na}_{2} \mathrm{~S}_{2} \mathrm{O}_{3}$ solution, recorded at regular intervals of time. A selected set of SHINERS spectra for the $100-550 \mathrm{~cm}^{-1}$ region are displayed in Figures 3A and 4, respectively. They are marked as a time elapsed after the addition of ammonia to the leaching solution. The overall shape of spectra in Figure 3A is similar to the spectrum shown in Figure 1 indicating that the broad envelope of these spectral features consists of bands corresponding to the components of the passive layer as assigned in Figure 1. All bands in Figure 3A decrease as a function of time, albeit at different rates, suggesting that ammonia is assisting the removal of elemental sulfur species, most notably sulfides $\left(309 \mathrm{~cm}^{-1}\right)$, cyclo-S $8\left(474,218\right.$, and $\left.152 \mathrm{~cm}^{-1}\right)$ and polysulfides/polythionates $\left(459 \mathrm{~cm}^{-1}\right)$ present at the gold-electrolyte interface.

To correlate changes in the composition of the passive layer to the changes in the dissolution rate, the intensity of the selected sulfur bands are plotted in Figure 2C as a function of the dissolution time, before and after the addition of ammonia at the $1000 \mathrm{~min}$ mark. These bands correspond to; (A) sulfides at $309 \mathrm{~cm}^{-1},(\bullet)$ cyclo-S at $218 \mathrm{~cm}_{8}^{-1}$, 
polysulfide/polythionate chains at $459 \mathrm{~cm}^{-1}$ and (\$) gold-thiosulfate complex at $\sim 379 \mathrm{~cm}^{-1}$. In order to visualize the effect of ammonia addition on the composition of the passive layer, the band intensities were normalized with respect to the intensities measured at time $1000 \mathrm{~min}$, which is at just before addition of $\mathrm{NH}_{4} \mathrm{OH}$. The gold-thiosulfate band was normalized at $\mathrm{t}=0 \mathrm{~min}$ and only plotted to $500 \mathrm{~min}$ as it becomes overly convoluted with the passive layer bands at longer immersions. Further, as already discussed in our previous paper [10], the fast initial decrease of the leaching rate $(t=0$ to $100 \mathrm{~min})$ correlates well with the decrease in the surface concentration of the gold-thiosulfate complex. The results show that the decrease in the normalized intensity of all three sulfur bands after $\mathrm{NH}_{4} \mathrm{OH}$ addition $(t>1000 \mathrm{~min})$ correlates well with the increase in the gold dissolution rate shown in Figure 2B. This correlation suggests that ammonia removes elemental sulfur and that the presence of elemental sulfur in the interfacial region inhibits the gold dissolution reaction. The data also shows at approximately 400 min after addition of ammonia the amount of sulfur species in the passive layer starts to increase.

To explore the order by which ammonia is degrading the passive layer, generalized 2DCOS analysis of the sequentially acquired spectra (Figure 3A) was employed. This analysis can provide useful information in which order the sulfur species are removed from the passive layer by ammonia. The synchronous and asynchronous 2DCOS spectra are displayed in Figures $3 \mathrm{~B}$ and $3 \mathrm{C}$, respectively. Strong positive cross-correlation squares can be observed in Figure 3B between many of the identified bands suggesting the change in spectral intensity of all these bands occurs in the same direction. However, in the asynchronous spectrum (Figure 3C), the negative cross-correlation bands at $(309,459)$ and $(218,459)$ suggest that the changes in the spectral intensity related to polysulfides/polythionates, i.e. $459 \mathrm{~cm}^{-1}$, occurs prior to that of sulfides, at $309 \mathrm{~cm}^{-1}$ and cylo-S 8 at $218 \mathrm{~cm}^{-1}$. In addition, the positive $(218,309)$ band indicates that spectral changes corresponding to cylo- $\mathrm{S}_{8}$ take place before spectral changes corresponding to sulfides. Therefore, the 2DCOS analysis revealed that after addition of ammonia the polysulfides/polytionates appear to be removed first, they are followed by the removal of cylo- $\mathrm{S}_{8}$ and sulfides at the end. Previous research, has shown that amines and other nucleophiles such as cyanide [42], sulfides [43], phosphines [44], can cause spontaneous ring opening of cyclo-S 8 forming polysulfides which can then undergo further attack via S-S bond cleavage [45]. From these observations it could be hypothesized that additives like ammonia, under typical gold leaching conditions, may chemically interact with the elemental sulfur layer that has been formed at the gold-electrolyte interface.

Ammonia is known to adsorb on gold surfaces exhibiting SERS bands in the $700-600$ $\mathrm{cm}^{-1}$ and $400-350 \mathrm{~cm}^{-1}$ regions [46]. To find spectroscopic evidence of ammonia adsorption, Figure 4 plots SHINERS spectra in the $1100-600 \mathrm{~cm}^{-1}$ region, recorded after the addition of $\mathrm{NH}_{4} \mathrm{OH}$ to the $0.10 \mathrm{M} \mathrm{Na}_{2} \mathrm{~S}_{2} \mathrm{O}_{3}$ electrolyte. The SHINERS spectra displays several distinct bands located at 1063, 1040, 1025, and $998 \mathrm{~cm}^{-1}$, which correlate well with previously reported $v(\mathrm{SO})$ values from polythionates with $n \geq 4$, the gold-thiosulfate complex, and thiosulfate [3-6,47-50]. The weak, broad band observed between $900-750 \mathrm{~cm}^{-1}$ which remains fairly consistent after the addition of ammonia may be associated with oxide formation, e.g. $v(\mathrm{AuO}$ or $\mathrm{AuOH})$, on the polycrystalline gold surface [52]. Upon addition of $\mathrm{NH}_{4} \mathrm{OH}$, a strong band at ca. $673 \mathrm{~cm}^{-1}$, tentatively assigned as $v_{\mathrm{s}}(\mathrm{SNS})$, appears initially and grows in intensity until $21 \mathrm{~min}$ where it begins to decrease and eventually disappears altogether after $61 \mathrm{~min}$. A second band positioned at $881 \mathrm{~cm}^{-1}$ appears after $20 \mathrm{~min} \mathrm{NH}_{4} \mathrm{OH}$ addition which may correspond with $v_{\text {as }}$ (SNS) [51]. The appearance of these bands indicates that ammonia plays a critical role by interacting 
directly with the sulfur passive layer and chemically degrades and removes sulfur species from the interfacial region through direct bonding to adsorbed sulfur species.

\subsection{Gold leaching in thiosulfate solutions with copper}

Figures $5 \mathrm{~A}$ and $5 \mathrm{~B}$ compare the $E_{\mathrm{M}}$ and $R_{\mathrm{Au}}$ values of a freshly polished and electrochemically clean gold electrode recorded during three independent 2500 min gold leaching experiments. The black points plot the data obtained for gold leaching in $0.10 \mathrm{M}$ $\mathrm{Na}_{2} \mathrm{~S}_{2} \mathrm{O}_{3}$ with $\mathrm{pH}=10.0$ (experiment 1-reference curves). The blue points represent measurements of experiment 2 performed in $0.10 \mathrm{M} \mathrm{Na}_{2} \mathrm{~S}_{2} \mathrm{O}_{3}+10 \mathrm{mM} \mathrm{CuSO} 4(\mathrm{pH}=10.0)$ solution. Finally, red points plot the data of experiment 3 in which $10 \mathrm{mM} \mathrm{CuSO}_{4}$ was added to the $0.10 \mathrm{M} \mathrm{Na}_{2} \mathrm{~S}_{2} \mathrm{O}_{3}$ solution after $1000 \mathrm{~min}$ of gold dissolution. For the $0.10 \mathrm{M} \mathrm{Na} 2 \mathrm{~S}_{2} \mathrm{O}_{3}+10$ $\mathrm{mM} \mathrm{CuSO}_{4}$ electrolyte, the initial $E_{\mathrm{M}} \sim 0.010 \mathrm{~V}$ vs. SCE is more positive with respect to the initial value of the solution without copper $\left(E_{\mathrm{M}}=-0.112 \mathrm{~V}\right)$. In the presence of copper, the initial $R_{A u} \sim 135.8 \pm 30.2 \mathrm{nmol} \mathrm{m}^{-2} \mathrm{~s}^{-1}$ is an order of magnitude larger than in the pure $0.10 \mathrm{M} \mathrm{Na}_{2} \mathrm{~S}_{2} \mathrm{O}_{3}$ solution (initial $R_{A u} \sim 5.2 \mathrm{nmol} \mathrm{m} \mathrm{m}^{-2}$ ). Within the first 60 minutes the $E_{M}$ and $R_{A u}$ values for $0.10 \mathrm{M} \mathrm{Na}_{2} \mathrm{~S}_{2} \mathrm{O}_{3}+10 \mathrm{mM} \mathrm{CuSO}_{4}$ solution quickly decrease reaching a minimum at $-0.078 \pm$ $0.004 \mathrm{~V}$ vs. SCE and $20.8 \pm 0.1 \mathrm{nmol} \mathrm{m}^{-2} \mathrm{~s}^{-1}$, respectively. The $E_{\mathrm{M}}$ value increases somewhat after reaching the minimum, but over extended times remains fairly constant around $-0.060 \pm$ $0.003 \mathrm{~V}$. For clarity the error bars have been omitted from Figure 5. As evidenced from the shift in the $E_{\mathrm{M}}$ and $R_{\mathrm{Au}}$ values the addition of $\mathrm{Cu}^{2+}$ significantly alters the surface chemistry. Previously, this change has been attributed to the ability of $\mathrm{Cu}^{2+}$ to act as a better redox couple relative to dissolved oxygen. Upon conversion of the $\mathrm{Cu}^{2+}$ to $\mathrm{Cu}^{+}$, dissolved oxygen in the bulk is able to regenerate the $\mathrm{Cu}^{2+}$ ion for further leaching. The $E_{\mathrm{M}}$ values are always shifted about $0.080 \mathrm{~V}$ more positive than in the electrolyte without copper. However, the average $R_{\mathrm{Au}}$ in the presence of copper rises at extended leaching times suggesting that $\mathrm{Cu}^{2+}$ plays a very complex role in the gold dissolution mechanism.

In experiment 3, $10 \mathrm{mM} \mathrm{CuSO}_{4}$ (final concentration) was added into the $0.10 \mathrm{M} \mathrm{Na}_{2} \mathrm{~S}_{2} \mathrm{O}_{3}$ electrolyte solution after the gold electrode was exposed for $1000 \mathrm{~min}$. The $E_{\mathrm{M}}$ and $R_{\text {Au }}$ values were then continually monitored for an additional $1500 \mathrm{~min}$. Upon addition of $\mathrm{Cu}^{2+}$, a large positive shift in the $E_{\mathrm{M}}$ from $-0.135 \mathrm{~V}$ to $-0.032 \mathrm{~V}$ vs. SCE and a corresponding increase in the $R_{\text {Au }}$ value, from 3.7 to $60.8 \mathrm{nmol} \mathrm{m}^{-2} \mathrm{~s}^{-1}$, are observed. After the initial positive shift in $E_{\mathrm{M}}$ upon $\mathrm{Cu}^{2+}$ addition the mixed potential quickly decreases and then slowly approaches the values measured in experiment 2 for $0.10 \mathrm{M} \mathrm{Na}_{2} \mathrm{~S}_{2} \mathrm{O}_{3}+10 \mathrm{mM} \mathrm{CuSO}_{4}$ solution. The addition of $\mathrm{Cu}^{2+}$ also causes a spike on the $R_{\mathrm{Au}}$ versus leaching time plot followed by a progressive increase of $R_{\mathrm{Au}}$. The rates of gold dissolution after $\mathrm{Cu}^{2+}$ are much higher than in the pure $0.10 \mathrm{M} \mathrm{Na}_{2} \mathrm{~S}_{2} \mathrm{O}_{3}$, however lower than in experiment 2 where copper was present in the leaching solution since initial exposure of the gold electrode. The higher $R_{\mathrm{Au}}$ values in the presence of $\mathrm{Cu}^{2+}$ indicate that $\mathrm{Cu}^{2+}$ plays a complex interfacial role by; (a) promoting gold oxidation, and (b) interacting with elemental sulfur species present in the interfacial region. The shift in the mixed potential and large increase in the leaching kinetics are consistent with the previous reports of enhanced gold dissolution in the presence of copper $[1,7,23,41]$.

To characterize changes in the composition of surface species upon the addition of $\mathrm{Cu}^{2+}$, a freshly prepared $\mathrm{Au} / \mathrm{SHINs}$ electrode was exposed to a $0.10 \mathrm{M} \mathrm{Na} \mathrm{S}_{2} \mathrm{O}_{3}$ electrolyte for 1000 min and characterized with SHINERS (measurements complementary to experiment 3). Figure 6A displays the sequentially acquired SHINERS spectra upon addition of $10 \mathrm{mM} \mathrm{CuSO}$. After 
addition of $\mathrm{Cu}^{2+}$, a very rapid decrease in the spectral intensity of the polysulfide bands, ca. 459 $\mathrm{cm}^{-1}$, and those related to cyclo- $\mathrm{S}_{8}, \mathrm{ca} .474,218$ and $152 \mathrm{~cm}^{-1}$, are observed.

To allow comparison of the changes in surface composition to the changes in $E_{\mathrm{M}}$ and $R_{\mathrm{Au}}$, the normalized SERS intensities due to polysulfide chains $\left(459 \mathrm{~cm}^{-1}\right)$, gold sulfide $\left(309 \mathrm{~cm}^{-1}\right)$, cyclo-S $S_{8}\left(218 \mathrm{~cm}^{-1}\right)$ and copper sulfide $\left(140 \mathrm{~cm}^{-1}\right)$ are plotted in Figure 5C. Upon addition of copper, the passive layer bands corresponding to polysulfide chains and cyclo- $\mathrm{S}_{8}$ rapidly decrease to approximately $10 \%$ of their intensity. The gold-sulfide band also decreases by about $30 \%$. The SHINERS spectra reveal a new band at $140 \mathrm{~cm}^{-1}$ that could be assigned to the presence of covellite $(\mathrm{CuS})$ at the surface [53-56]. The data indicates that long polysulfides/polythionates and cyclo- $\mathrm{S}_{8}$ are quickly converted to short chains, with $n$ less than 4 . The gold and copper sulfides appear to be the predominant components of the stable passive layer at longer times, $t>$ 200 mins after $\mathrm{Cu}^{2+}$ addition.

More information about the sequential changes of these bands is provided by the 2DCOS analysis. The synchronous and asynchronous 2DCOS spectra generated from the time dependent spectra recorded after addition of $\mathrm{Cu}^{2+}$ are represented as Figure $6 \mathrm{~B}$ and $6 \mathrm{C}$, respectively. Strong positive cross-correlation squares drawn in the synchronous spectrum (Figure 6B) between (459, 474), (459, 218), and $(459,152)$ indicate that these bands change in the same direction. In contrast, negative cross correlation bands between $140 \mathrm{~cm}^{-1}$ and all other observed features in the spectrum indicates the $140 \mathrm{~cm}^{-1}$ band (covellite) change in the opposite direction relative to the other spectral features. In fact Figure 6A shows that the spectral variation at $140 \mathrm{~cm}^{-1}$ increases while other features decrease with time. In the asynchronous, spectrum Figure $6 \mathrm{C}$, the cross correlation bands at $140 \mathrm{~cm}^{-1}$ are positive. Since the corresponding cross correlation bands in the synchronous spectrum, Figure $6 \mathrm{~B}$, were negative, the intensity variation related to covellite follows after the change of all other features in the spectrum. In other words, the cyclo- $\mathrm{S}_{8}$, long and short chain polysulfides are removed first before covellite is formed. Further, in the asynchronous spectrum the cross correlation bands present at $218 \mathrm{~cm}^{-1}, 400$ and $426 \mathrm{~cm}^{-1}$ (short chain), and $459 \mathrm{~cm}^{-1}$ (long chain polymeric sulfur) are also positive. These cross correlation bands are also positive in the synchronous spectrum indicating that changes in the $218 \mathrm{~cm}^{-1} \mathrm{band}$ are taking place before changes of the polysulfide bands. This means that the cyclo- $\mathrm{S}_{8}$ is removed by addition of $\mathrm{Cu}^{2+}$ before polymeric sulfides. Finally, the $(309,459)$ and $(426,459)$ bands are negative in the asynchronous spectrum while they are positive in the synchronous spectrum. This behaviour indicates that the changes of the long chain polysulfide band $\left(459 \mathrm{~cm}^{-}\right.$ $\left.{ }^{1}\right)$ take place before changes of the AuS band $\left(309 \mathrm{~cm}^{-1}\right)$ and short chain polysulfide band (426 $\mathrm{cm}^{-1}$ ). Thus the $2 \mathrm{DCOS}$ analysis provided unique information that addition of $\mathrm{Cu}^{2+}$ to the thiosulfate solution removes first cyclo- $\mathrm{S}_{8}$, followed by long-chain polysulfides, then by removal of short chain polysulfides from the passive layer. However, a new species $\mathrm{CuS}$ appears in the surface layer. The formation of $\mathrm{CuS}$ on the gold surface would be of concern during a typical gold leaching process as $\mathrm{Cu}^{2+}$ is consumed to form $\mathrm{CuS}$. However, since the leaching rate slowly increases when the amount of $\mathrm{CuS}$ increases with time, the data suggests that formation of $\mathrm{CuS}$ on the surface does not have as significant of a passivating effect.

\section{Conclusions}

Shell-isolated nanoparticle-enhanced Raman spectroscopy (SHINERS), generalized twodimensional correlation spectroscopy (2DCOS), and electrochemistry were used to investigate the gold leaching kinetics and understand the role copper and ammonia play in the interfacial 
region. Consistent with previous reports the overall kinetics of gold leaching were found to be higher in the presence of ammonia and copper. However, addition of ammonia after 1000 min of exposure of a polycrystalline gold electrode to a $0.1 \mathrm{M} \mathrm{Na} 2 \mathrm{~S}_{2} \mathrm{O}_{3}$ electrolyte was found to significantly increase the leaching rate. Characterization with SHINERS revealed direct evidence of degradation of the elemental sulfur species, i.e. cyclo- $\mathrm{S}_{8}$, polysulfide chains, and adsorbed sulfides, by ammonia. Exposure of a similar passive layer to copper cations displayed reduction of cyclo-S $\mathrm{S}_{8}$ and polysulfide species to form a stable layer of $\mathrm{CuS}$. Ammonia and copper play a convoluted mechanism of preventing passive layer formation and increasing the oxidation of gold to achieve higher gold extraction efficiencies. The observed decrease in passive layer species present in the interfacial region and the simultaneous increase in the gold dissolution rate, $R_{\mathrm{Au}}$, with the additives present during gold leaching experiments supports previously reported observations of beneficial effects towards the gold leaching kinetics in the presence of $\mathrm{Cu}^{2+}$ and ammonia in thiosulfate lixiviants.

\section{Acknowledgements}

The authors are grateful to the Barrick Gold Corporation and the Natural Science and Engineering Research Council of Canada (NSERC) for financial support (Grant CRDPJ 434421 12).

\section{References}

[1] K. Watling, G.A. Hope, M.I. Jeffrey, R. Woods, Surface Products on Gold Leached in Ammoniacal Copper(II) Thiosulfate Solution, in: ECS Trans., ECS, (2006) 121-132.

[2] K. Watling, G. Parker, G.A. Hope, R. Woods, A SERS Investigation of the Interaction of Sulfur with Gold, in: ECS Trans., ECS, (2006) 61-72.

[3] M.I. Jeffrey, K. Watling, G.A. Hope, R. Woods, Identification of surface species that inhibit and passivate thiosulfate leaching of gold, Miner. Eng. 21 (2008) 443-452.

[4] J.Y. Baron, J. Mirza, E.A. Nicol, S.R. Smith, J.J. Leitch, Y. Choi, et al., SERS and electrochemical studies of the gold-electrolyte interface under thiosulfate based leaching conditions, Electrochim. Acta. 111 (2013) 390-399.

[5] E.A. Nicol, J.Y. Baron, J. Mirza, J.J. Leitch, Y. Choi, J. Lipkowski, Surface-enhanced Raman spectroscopy studies of the passive layer formation in gold leaching from thiosulfate solutions in the presence of cupric ion, J. Solid State Electrochem. 18 (2013) 1469-1484.

[6] J. Mirza, S.R. Smith, J.Y. Baron, Y. Choi, J. Lipkowski, A SERS characterization of the stability of polythionates at the gold-electrolyte interface, Surf. Sci. 631 (2015) 196-206.

[7] J. Marsden, I. House, The Chemistry of Gold Extraction, 2nd ed., Society for Mining, Metallurgy, and Exploration, Littleton, CO, USA, 2006.

[8] M.G. Aylmore, D.M. Muir, Thiosulfate leaching of gold - A review, Miner. Eng. 14 (2001) 135-174.

[9] A.M. Sullivan, P.A. Kohl, Electrochemical Study of the Gold Thiosulfate Reduction, J. Electrochem. Soc. 144 (1997) 1686-1690.

[10] S.R. Smith, J.J. Leitch, C. Zhou, J. Mirza, S.B. Li, X.D. Tian, et al., Quantitative SHINERS Analysis of Temporal Changes in the Passive Layer at a Gold Electrode 
Surface in a Thiosulfate Solution., Anal. Chem. 87 (2015) 3791-9.

[11] M. Lampinen, A. Laari, I. Turunen, Ammoniacal thiosulfate leaching of pressure oxidized sulfide gold concentrate with low reagent consumption, Hydrometallurgy. 151 (2015) 1-9.

[12] J. Aromaa, L. Rintala, M. Kahari, O. Forsen, Dissolution of gold with cyanide replacing reagents, Physicochem. Probl. Miner. Process. Vol. 51, i (2015).

[13] Y. Nie, Q. Yu, X. Hu, F. Zi, H. Yu, The Effect of Ammonia on the Anodic Process of Gold in Copper-Free Thiosulfate Solution, J. Electrochem. Soc. 163 (2016) E123-E129.

[14] S.R. Smith, E. Guerra, S. Siemann, J.L. Shepherd, Au dissolution during the anodic response of short-chain alkylthiols with polycrystalline Au electrodes, Electrochim. Acta. 56 (2011) 8291-8298.

[15] A.G. Zelinsky, O.N. Novgorodtseva, Effect of thiourea on the rate of anodic processes at gold and graphite electrodes in thiosulfate solutions, Electrochim. Acta. 109 (2013) 482488 .

[16] A.G. Zelinsky, Anode current on gold in mixed thiosulfate-sulfite electrolytes, Electrochim. Acta. 154 (2015) 315-320.

[17] D. Feng, J.S.J. van Deventer, Thiosulphate leaching of gold in the presence of ethylenediaminetetraacetic acid (EDTA), Miner. Eng. 23 (2010) 143-150.

[18] Y. Nie, H. Chi, F. Zi, X. Hu, H. Yu, S. He, The effect of cobalt and nickel ions on gold dissolution in a thiosulfate-ethylenediamine (en)- $\mathrm{Cu}^{2+}$ system, Miner. Eng. 83 (2015) 205-210.

[19] I. Chandra, M.I. Jeffrey, An electrochemical study of the effect of additives and electrolyte on the dissolution of gold in thiosulfate solutions, Hydrometallurgy. 73 (2004) 305-312.

[20] G. Senanayake, Analysis of reaction kinetics, speciation and mechanism of gold leaching and thiosulfate oxidation by ammoniacal copper(II) solutions, Hydrometallurgy. 75 (2004) 55-75.

[21] G. Senanayake, Gold leaching by thiosulphate solutions: a critical review on copper(II)thiosulphate-oxygen interactions, Miner. Eng. 18 (2005) 995-1009.

[22] A.C. Grosse, G.W. Dicinoski, M.J. Shaw, P.R. Haddad, Leaching and recovery of gold using ammoniacal thiosulfate leach liquors (a review), Hydrometallurgy. 69 (2003) 1-21.

[23] G. Senanayake, The role of ligands and oxidants in thiosulfate leaching of gold, Gold Bull. 38 (2005) 170-179.

[24] J. Webster, The solubility of gold and silver in the system Au-Ag-S-O $-\mathrm{O}_{2}-\mathrm{H}_{2} \mathrm{O}$ at $25^{\circ} \mathrm{C}$ and 1 atm., Geochim. Cosmochim. Acta. 50 (1986) 1837-1845.

[25] M. Pilśniak, A.W. Trochimczuk, W. Apostoluk, The Uptake of Gold(I) from Ammonia Leaching Solution by Imidazole Containing Polymeric Resins, Sep. Sci. Technol. 44 (2009) 1099-1119.

[26] L.H. Skibsted and J. Bjerrum, Studies on gold complexes. II. The equilibrium between gold(I) and gold(III) in the ammonia system and the standard potentials of the couples involving gold, diamminegold(I), and tetramminegold(III), Acta Chem. Scand. 28A (1974) 764-770. 
[27] P.L. Breuer and M.I. Jeffrey, Thiosulfate leaching kinetics of gold in the presence of copper and ammonia. Miner. Eng. 13 (2000) 1071-1081.

[28] P.L. Breuer and M.I. Jeffrey, An electrochemical study of gold leaching in thiosulfate solutions containing copper and ammonia. Hydrometallurgy. 65 (2002) 145-157.

[29] J.F. Li, Y.F. Huang, Y. Ding, Z.L. Yang, S.B. Li, X.S. Zhou, et al., Shell-isolated nanoparticle-enhanced Raman spectroscopy., Nature. 464 (2010) 392-5.

[30] J.F. Li, S.Y. Ding, Z.L. Yang, M.L. Bai, J.R. Anema, X. Wang, et al., Extraordinary enhancement of Raman scattering from pyridine on single crystal Au and Pt electrodes by shell-isolated Au nanoparticles., J. Am. Chem. Soc. 133 (2011) 15922-5.

[31] J.F. Li, X.D. Tian, S.B. Li, J.R. Anema, Z.L. Yang, Y. Ding, et al., Surface analysis using shell-isolated nanoparticle-enhanced Raman spectroscopy., Nat. Protoc. 8 (2013) 52-65.

[32] X.D. Tian, B.J. Liu, J.F. Li, Z.L. Yang, B. Ren, Z.Q. Tian, SHINERS and plasmonic properties of $\mathrm{Au}$ Core $\mathrm{SiO} 2$ shell nanoparticles with optimal core size and shell thickness, J. Raman Spectrosc. 44 (2013) 994-998.

[33] D. Pletcher, F.C. Walsh, Industrial Electrochemistry, 2nd ed., Springer Netherlands, Dordrecht, 1993.

[34] A.J. Bard, L.R. Faulkner, Electrochemical Methods: Fundamentals and Applications, 2nd ed., John Wiley \& Sons, Hoboken, NJ, USA, 2000.

[35] J.Y. Baron, G. Szymanski, J. Lipkowski, Electrochemical methods to measure gold leaching current in an alkaline thiosulfate solution, J. Electroanal. Chem. 662 (2011) 5763.

[36] I. Noda, Generalized Two-Dimensional Correlation Method Applicable to Infrared, Raman, and Other Types of Spectroscopy, Appl. Spectrosc. 47 (1993) 1329-1336.

[37] I. Noda, A.E. Dowrey, C. Marcoli, G.M. Story, Y. Ozaki, Generalized Two-Dimensional Correlation Spectroscopy, Appl. Spectrosc. 54 (2000) 236A-248A.

[38] I. Noda, Y. Ozaki, Two-Dimensional Correlation Spectroscopy: Applications in Vibrational and Optical Spectroscopy, John Wiley \& Sons, Hoboken, NJ, USA, 2005.

[39] I. Noda, Two-dimensional codistribution spectroscopy to determine the sequential order of distributed presence of species, J. Mol. Struct. 1069 (2014) 50-59.

[40] M.I. Jeffrey, P.L. Breuer, W.L. Choo, A kinetic study that compares the leaching of gold in the cyanide, thiosulfate, and chloride systems, Metall. Mater. Trans. B. 32 (2001) 979986.

[41] S. Zhang, M.J. Nicol, An electrochemical study of the dissolution of gold in thiosulfate solutions. Part II. Effect of Copper, J. Appl. Electrochem. 35 (2005) 339-345.

[42] A. Senning, Sulfur in organic and inorganic chemistry, Dekker, 1971.

[43] K. Okamoto, T. Yamamoto, T. Kanbara, Efficient Synthesis of Thiobenzanilides by Willgerodt-Kindler Reaction with Base Catalysts, Synlett. 2007 (2007) 2687-2690.

[44] F.P. Daly, C.W. Brown, Raman spectra of sodium tetrasulfide in primary amines. Evidence for sulfide $\left(\mathrm{S}_{4}{ }^{2-}\right.$ and $\left.\mathrm{S}_{8}{ }^{\mathrm{n}-}\right)$ ions in rhombic sulfur-amine solutions, J. Phys. Chem. 79 (1975) 350-354. 
[45] R. Steudel, B. Eckert, Elemental Sulfur and Sulfur-Rich Compounds I, in: R. Steudel (Ed.), Top. Curr. Chem., Springer Berlin Heidelberg, Berlin, Heidelberg, 2003: 1-80.

[46] A.C.A. de Vooys, M.F. Mrozek, M.T.M. Koper, R.A. van Santen, J.A.R. van Veen, M.J. Weaver, The nature of chemisorbates formed from ammonia on gold and palladium electrodes as discerned from surface-enhanced Raman spectroscopy, Electrochem. Commun. 3 (2001) 293-298.

[47] L. Rintoul, K. Crawford, H.F. Shurvell, P.M. Fredericks, Surface-enhanced Raman scattering of inorganic oxoanions, Vib. Spectrosc. 15 (1997) 171-177.

[48] Z. Gabelica, Structural study of solid inorganic thiosulfates by infrared and Raman spectroscopy, J. Mol. Struct. 60 (1980) 131-138.

[49] J.A. Haigh, P.J. Hendra, A.J. Rowlands, I.A. Degen, G.A. Newman, Raman spectroscopy of thiosulphates, Spectrochim. Acta Part A Mol. Spectrosc. 49 (1993) 723-725.

[50] S. Sato, S. Higuchi, S. Tanaka, Identification and Determination of Oxygen-Containing Inorganosulfur Compounds by Laser Raman Spectrometry, Appl. Spectrosc. 39 (1985) 822-827.

[51] T. Chivers, C. Lau, Raman spectroscopic identification of the $\mathrm{S}_{4} \mathrm{~N}^{-}$and $\mathrm{S}_{3}{ }^{-}$ions in blue solutions of sulfur in liquid ammonia, Inorg. Chem. 21 (1982) 453-455.

[52] U. Zhumaev, A. V. Rudnev, J.F. Li, A. Kuzume, T.H. Vu, T. Wandlowski, Electrooxidation of $\mathrm{Au}(111)$ in contact with aqueous electrolytes: New insight from in situ vibration spectroscopy, Electrochim. Acta. 112 (2013) 853-863.

[53] K. Sasaki, Y. Nakamuta, T. Hirajima, O.H. Tuovinen, Raman characterization of secondary minerals formed during chalcopyrite leaching with Acidithiobacillus ferrooxidans, Hydrometallurgy. 95 (2009) 153-158.

[54] C.G. Munce, G.K. Parker, S.A. Holt, G.A. Hope, A Raman spectroelectrochemical investigation of chemical bath deposited $\mathrm{Cu}_{\mathrm{x}} \mathrm{S}$ thin films and their modification, Colloids Surfaces A Physicochem. Eng. Asp. 295 (2007) 152-158.

[55] G.K. Parker, R. Woods, G.A. Hope, Raman Investigation of Sulfide Leaching, in: F.M. Doyle, R. Woods (Eds.), Electrochem. Miner. Met. Process. VI Proc. Int. Symp., The Electrochemical Society, Pennington, NY, 2003: pp. 181-192.

[56] M. Ishii, K. Shibata, H. Nozaki, Anion Distributions and Phase Transitions in $\mathrm{CuS}_{1-\mathrm{x}} \mathrm{Se}_{\mathrm{x}}(\mathrm{x}$ = 0-1) Studied by Raman Spectroscopy, J. Solid State Chem. 105 (1993) 504-511. 


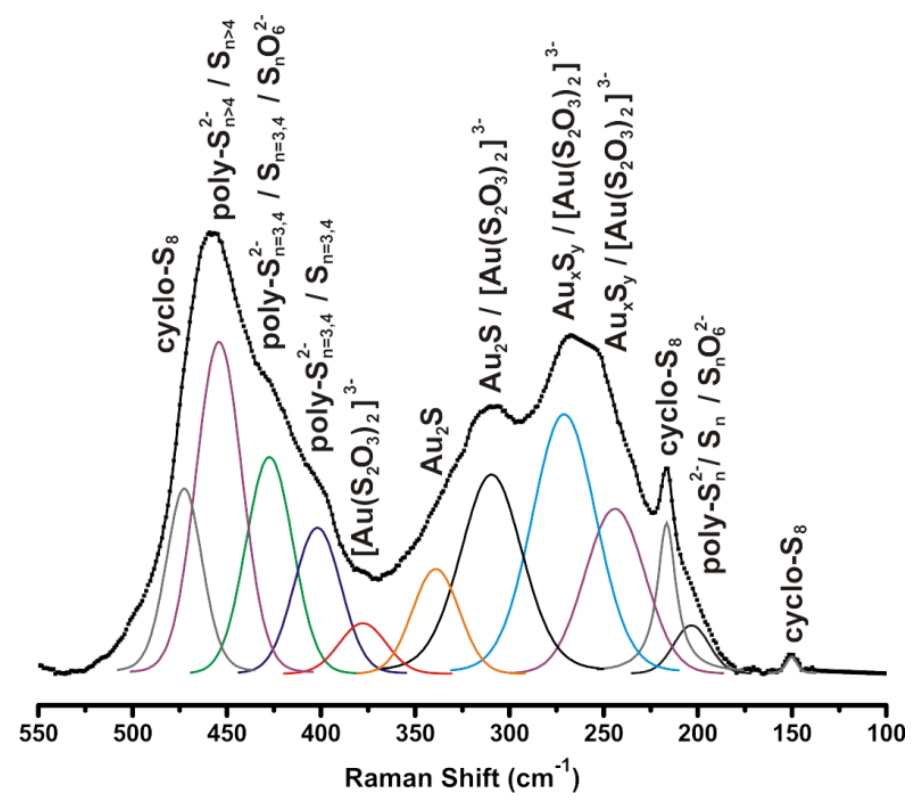

Figure 1: Deconvolution of the passive layer constituents formed on a SHINs modified polycrystalline gold electrode (Au/SHINs) after immersion in a $0.10 \mathrm{M} \mathrm{Na}_{2} \mathrm{~S}_{2} \mathrm{O}_{3}$ electrolyte $(\mathrm{pH}$ $=10.0$ ) for $1000 \mathrm{~min}$. 


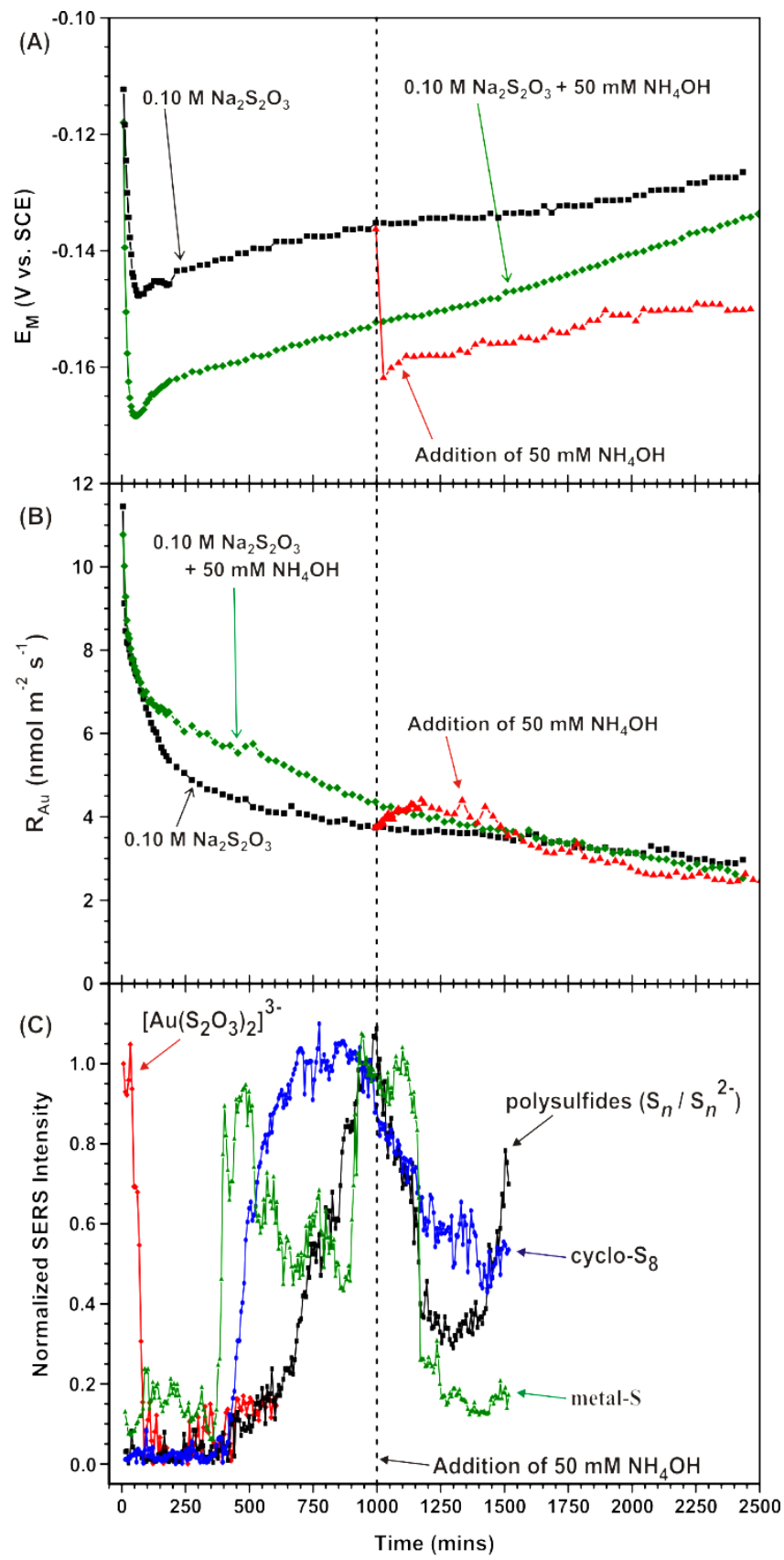

Figure 2: Average (A) $E_{\mathrm{M}}$ and (B) $R_{\mathrm{Au}}$ values measured as a function of immersion time of freshly polished polycrystalline gold electrode in electrolyte solutions of; ( $\mathbf{\square}) 0.10 \mathrm{M}$ $\mathrm{Na}_{2} \mathrm{~S}_{2} \mathrm{O}_{3}(\mathrm{pH}=10.0)$ for $2500 \mathrm{~min}$, ( $) 0.10 \mathrm{M} \mathrm{Na}_{2} \mathrm{~S}_{2} \mathrm{O}_{3}+50 \mathrm{mM} \mathrm{NH} 4 \mathrm{OH}(\mathrm{pH}=10.0)$ for $2500 \mathrm{~min}$, and $0.10 \mathrm{M} \mathrm{Na}_{2} \mathrm{~S}_{2} \mathrm{O}_{3}(\mathrm{pH}=10.0)$ for $1000 \mathrm{~min}$ followed by the addition of ( $\Delta$ ) $50 \mathrm{mM} \mathrm{NH}_{4} \mathrm{OH}$ for a sequential $1500 \mathrm{~min}$. (C) Normalized average SERS intensities

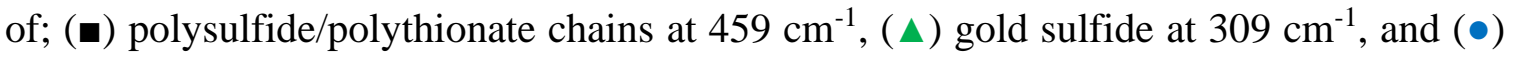
cyclo- $\mathrm{S}_{8}$ at $218 \mathrm{~cm}^{-1}$, recorded at the surface of the Au/SHINs electrode immersed in a $0.10 \mathrm{M} \mathrm{Na}_{2} \mathrm{~S}_{2} \mathrm{O}_{3}$ electrolyte $(\mathrm{pH}=10.0)$ for $1000 \mathrm{~min}$, followed by a subsequent 1500 min after the addition of $50 \mathrm{mM} \mathrm{NH}_{4} \mathrm{OH}$. 

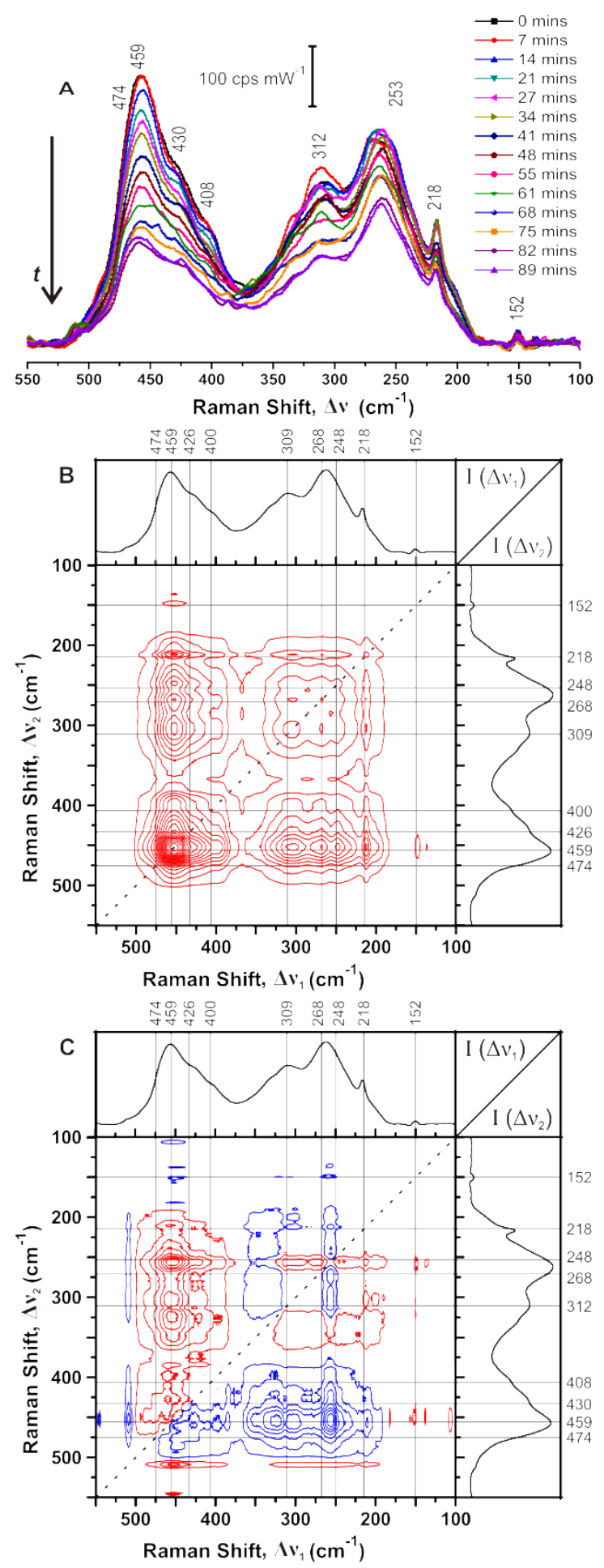

Figure 3: (A) Baselined corrected SERS spectra, 600-100 $\mathrm{cm}^{-1}$ region, of the Au/SHINs electrode collected upon the addition of $50 \mathrm{mM} \mathrm{NH} \mathrm{NH}_{4} \mathrm{OH}$ after immersion in a $0.10 \mathrm{M}$ $\mathrm{Na}_{2} \mathrm{~S}_{2} \mathrm{O}_{3}$ electrolyte $(\mathrm{pH}=10.0)$ for $1000 \mathrm{~min}$. Corresponding (B) synchronous and (C) asynchronous 2DCOS spectra generated as a function of immersion time; red - positive correlation bands, blue - negative correlation bands. Time-averaged spectra included for reference. 


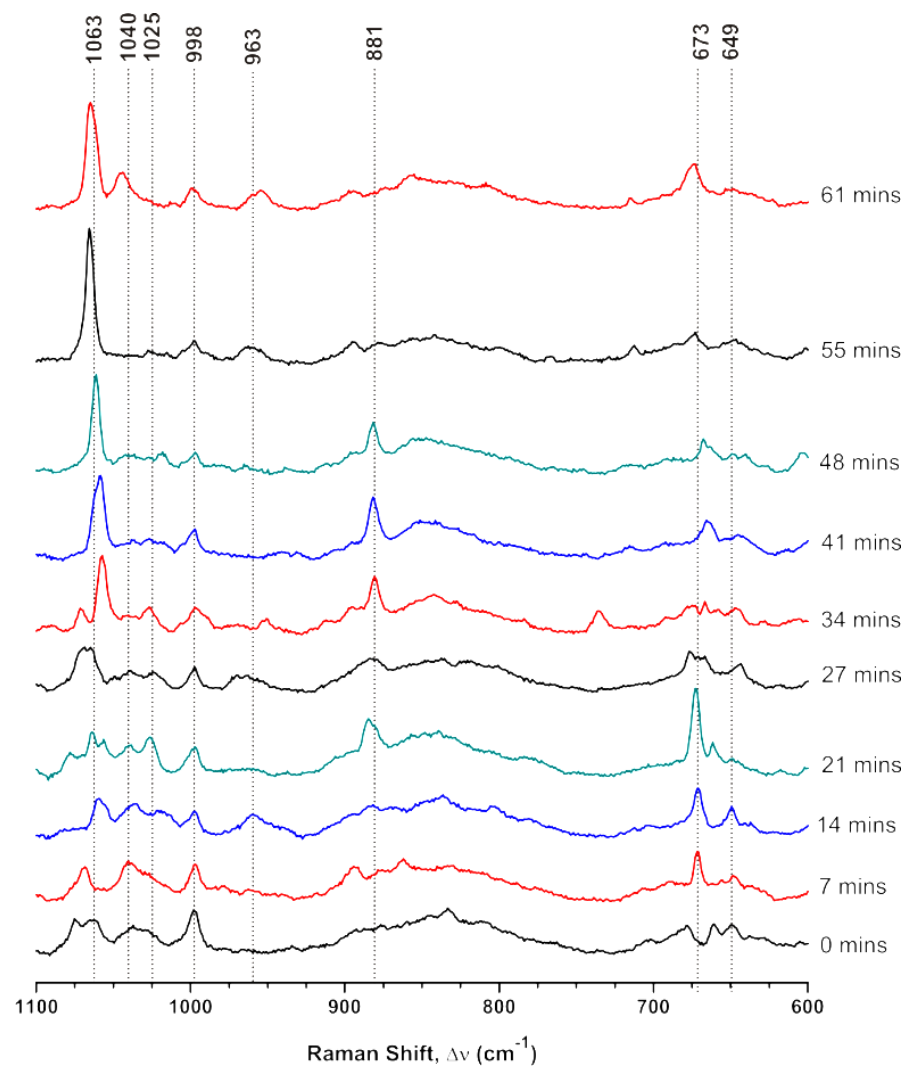

Figure 4: Baselined corrected SERS spectra, 1100-600 $\mathrm{cm}^{-1}$ region, of the Au/SHINs electrode collected upon the addition of $50 \mathrm{mM} \mathrm{NH} 4 \mathrm{OH}$ into the lixiviant after the gold electrode had been immersed into the $0.10 \mathrm{M} \mathrm{Na}_{2} \mathrm{~S}_{2} \mathrm{O}_{3}$ electrolyte $(\mathrm{pH}=10.0)$ for 1000 $\min$. 


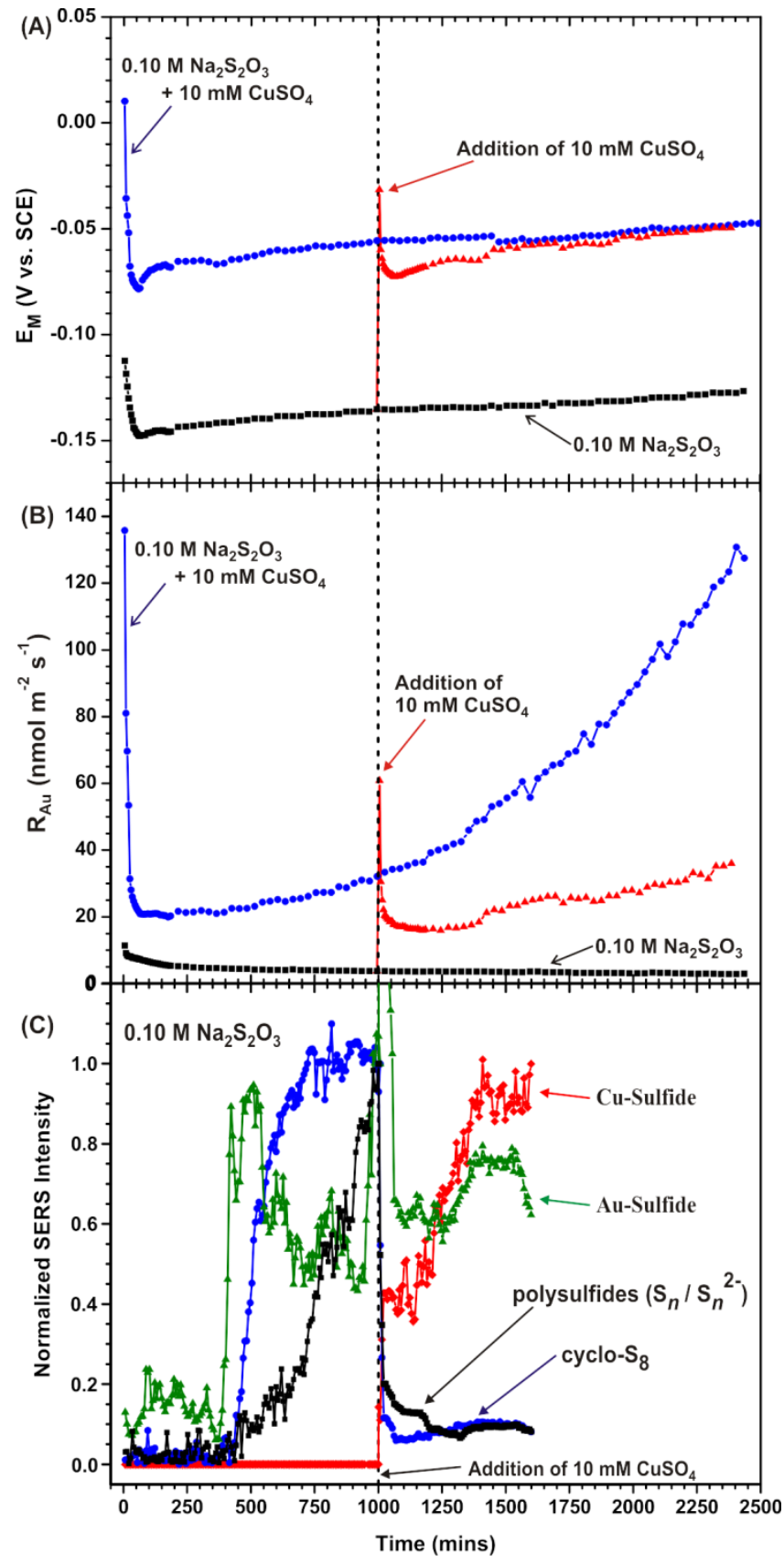

Figure 5: Averaged (A) $E_{\mathrm{M}}$ and (B) $R_{\text {Au }}$ values measured as a function of immersion time

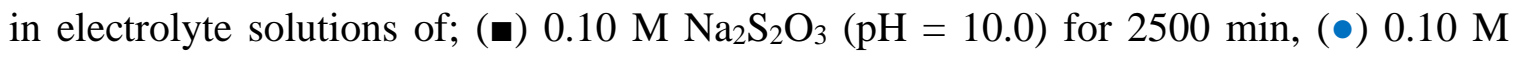
$\mathrm{Na}_{2} \mathrm{~S}_{2} \mathrm{O}_{3}+10 \mathrm{mM} \mathrm{CuSO} 4(\mathrm{pH}=10.0)$ for $2500 \mathrm{~min}$, and $0.10 \mathrm{M} \mathrm{Na}_{2} \mathrm{~S}_{2} \mathrm{O}_{3}(\mathrm{pH}=10.0)$ for $1000 \mathrm{~min}$ followed by the addition of ( $\$) 10 \mathrm{mM} \mathrm{CuSO}_{4}$ for a sequential $1500 \mathrm{~min}$. (C) normalized average SERS intensities of; ( $\mathbf{a})$ polysulfide chains (i.e. $n<4$ ) at 426 $\mathrm{cm}^{-1},(\diamond)$ covellite at $140 \mathrm{~cm}^{-1},(\boldsymbol{\Delta})$ metal-sulfur at $\sim 300 \mathrm{~cm}^{-1}$, and $(\bullet)$ cyclo-S 8 at 218 $\mathrm{cm}^{-1}$. 

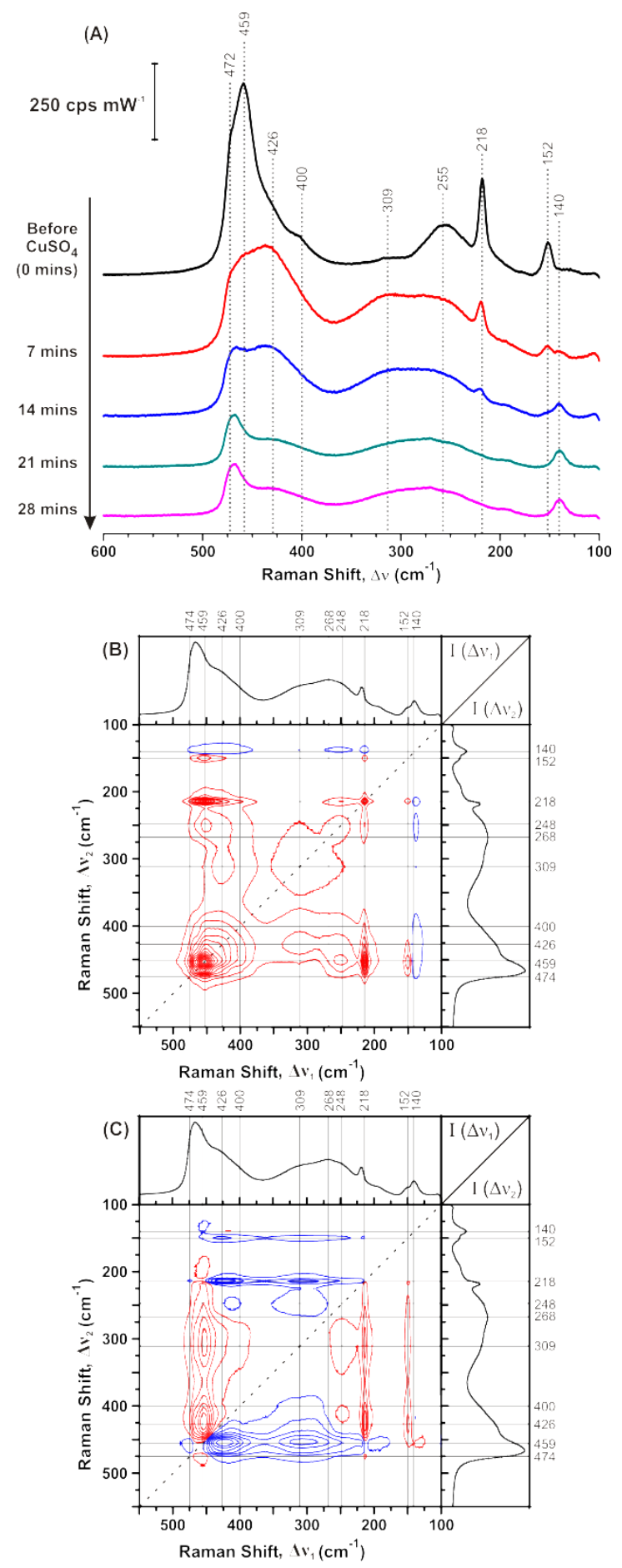

Figure 6: (A) Baseline corrected SHINERS spectra of the Au/SHINs electrode recorded upon the addition of $10 \mathrm{mM} \mathrm{CuSO}_{4}$ after immersion in a $0.10 \mathrm{M} \mathrm{Na}_{2} \mathrm{~S}_{2} \mathrm{O}_{3}$ electrolyte $(\mathrm{pH}$ $=10.0$ ) for 1000 mins; (B) synchronous and (C) asynchronous 2DCOS spectra generated as a function of immersion time from the SERS spectra (Figure 6A) recorded after $\mathrm{CuSO}_{4}$ addition; red - positive correlation bands, blue - negative correlation bands. Timeaveraged spectra included for reference on the two axes. 
Table 1: Summarized band positions of observed interfacial species with corresponding band assignments.

\begin{tabular}{|c|c|c|c|c|}
\hline \multirow{2}{*}{$\begin{array}{l}\text { Vibrational } \\
\text { Mode } \\
\text { Assignment }\end{array}$} & \multirow[b]{2}{*}{ Chemical Identity } & \multicolumn{3}{|c|}{ Observed Band Positions $\left(\mathrm{cm}^{-1}\right)$} \\
\hline & & $\begin{array}{c}\mathrm{Au} / \mathrm{SHINs} \\
0.1 \mathrm{M} \mathrm{Na} \mathrm{N}_{2} \mathrm{O}_{3} \\
(\leq 600 \mathrm{mins}) \\
\end{array}$ & $\begin{array}{c}\mathrm{Au} / \mathrm{SHINs} \\
0.1 \mathrm{M} \mathrm{Na} \mathrm{N}_{2} \mathrm{O}_{3} \\
\left.+50 \mathrm{mM} \mathrm{NH} \mathrm{NH}_{4} \mathrm{OH} \geq \mathbf{1 0 8 0} \text { mins }\right)\end{array}$ & $\begin{array}{c}\mathrm{Au} / \mathrm{SHINs} \\
\mathrm{0.1M} \mathrm{Na}_{2} \mathrm{~S}_{2} \mathrm{O}_{3} \\
+50 \mathrm{mMSO}_{4}(\geq 1080 \mathrm{mins})\end{array}$ \\
\hline$\delta(\mathrm{SSS})$ & $\mathrm{CuS}$ & - & - & 140 \\
\hline$\delta_{a s}(\mathrm{SSS})$ & cyclo- $\mathrm{S}_{8}$ & 151 & 152 & 152 \\
\hline$\delta_{s}(\mathrm{SSS})$ & cyclo- $\mathrm{S}_{8}$ & 218 & 218 & 218 \\
\hline$\delta_{S}(\mathrm{SSS})$ & $\mathrm{S}_{4} \mathrm{O}_{6}^{2-} / \mathrm{S}_{3} \mathrm{O}_{6}^{2-}$ & \multirow{2}{*}{266,309} & \multirow{2}{*}{$248,268,309$} & \multirow{2}{*}{268,309} \\
\hline $\begin{array}{l}v(\mathrm{CuS}) / \\
v\left(\mathrm{Au}_{x} \mathrm{~S}_{y}\right)\end{array}$ & $\begin{array}{c}\mathrm{CuS} / \\
\mathrm{Au}_{x} \mathrm{~S}_{y} /\left[\mathrm{Au}\left(\mathrm{S}_{2} \mathrm{O}_{3}\right)_{2}\right]^{3-}\end{array}$ & & & \\
\hline$v(\mathrm{AuS})$ & $\mathrm{Au}_{x} \mathrm{~S}_{y}$ & 326 & - & - \\
\hline \multirow{5}{*}{$v_{s}(\mathrm{SS})$} & {$\left[\mathrm{Au}\left(\mathrm{S}_{2} \mathrm{O}_{3}\right)_{2}\right]^{3-}$} & 378 & - & - \\
\hline & $\begin{array}{c}\mathrm{S}_{4} \mathrm{O}_{6}^{2-} / \mathrm{S}_{3} \mathrm{O}_{6}^{2-} / \\
\text { polymeric } \mathrm{S}_{3,4} / \mathrm{S}_{3,4}^{2-} \\
\end{array}$ & 408 & 400 & 400 \\
\hline & $\begin{array}{c}\mathrm{S}_{2} \mathrm{O}_{3}^{2-} / \\
\text { polymeric } \mathrm{S}_{3,4} / \mathrm{S}_{3,4}^{2-} \\
\end{array}$ & 430 & 426 & 426 \\
\hline & polymeric $\mathrm{S}_{n>4} / \mathrm{S}_{n>4}^{2-}$ & 459 & 459 & 459 \\
\hline & cyclo- $\mathrm{S}_{8}$ & 474 & 474 & 472 \\
\hline$v(\mathrm{SS})$ & $\mathrm{CuS}$ & - & - & 469 \\
\hline
\end{tabular}



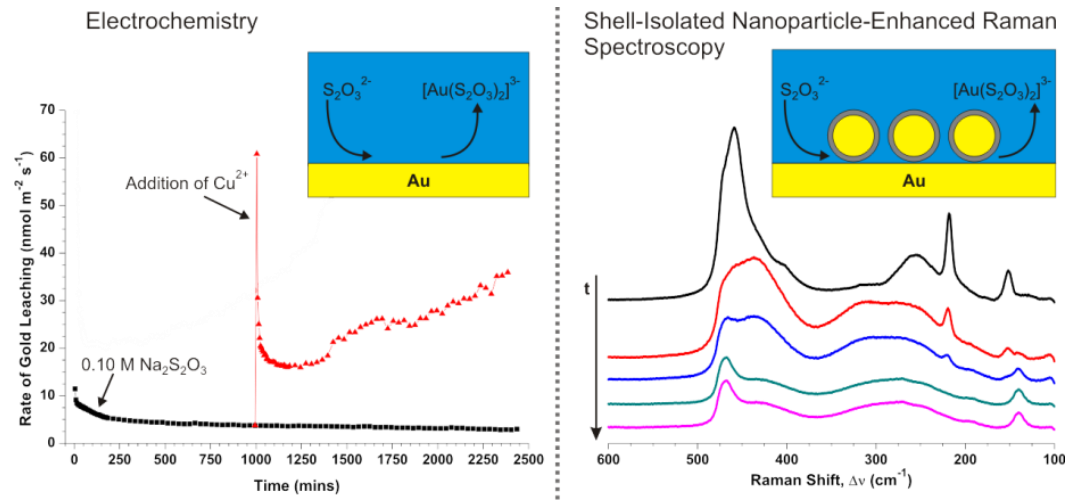